\title{
Environmental Pollution, Causes and Consequences
}

Pham van Huong ${ }^{1,2^{*}}$, Huynh Thanh Dat ${ }^{3}$, Nguyen Quoc Hung ${ }^{4}$

${ }^{1}$ University Bordeaux, ISM, Cours Liberation, Talence/Bordeaux, France.

${ }^{2}$ Elected member of the New York Academy of Sciences, USA.

${ }^{3}$ National University of HCMC, Thu Duc, HoChiMinhCity, Vietnam.

${ }^{4}$ Center of Analytical Service and Experimentation, Nguyen van Thu St, Ho Chi Minh City, Vietnam.

\section{Abstract}

Pollution induces harmful effects on environment and health security. Main deep causes will be analyzed including natural disasters like volcanoes eruption, climate change as well as and men-caused disasters which are nuclear explosions and dioxin sprays.

Keywords: Pollution; Health; Climate Change; Cancer; Nuclear Disasters.

\section{Introduction}

The global warming is direct consequence of volcanoes eruptions on earth and under oceans with big waves tsunamis in one hand and on the other hand the greenhouse effect. We must also take into account the effects of nuclear explosions and the explosure to dioxin and paraquat toxins.

\section{Main Causes and Discussion}

\section{Global warming}

The global warming is evident when looking at mountain Everest, at an altitude of 6000 meters there is no snow; as well as in Kunjerap, Pakistan frontier with China. We also saw the detachment of blue icebergs from the millenary glaciers near the South and North poles with a faster pace compared to the previous centuries [1] (Figure 1).

\section{Greenhouse effect}

In the conference on climate change in Copenhagen, nine years ago and Le Bourget/Paris in 2016, many international organizations have accused $\mathrm{CO} 2$, carbon dioxide as principal responsible of the greenhouse effect. According to chemical physics science [2-7], this assertion is a serious mistake intentionally or not. Any- way it's a great sin before public opinion of mankind.

When accused of $\mathrm{CO}_{2}$, is accused of most people who use motorcycles, cars, moving vehicles, motor freighter explosion. Every girl or boy from their secondary school knows that the combustion of hydrocarbon fuel gives not only $\mathrm{CO}_{2}$ but also water vapor $\mathrm{H}_{2} \mathrm{O}$. Spectroscopy indicates that the greenhouse effect of water vapor is a thousand times more important than that of $\mathrm{CO}_{2}$. (Figure 2)

Steam smoke when we see is the water droplets in liquid or solid form with a higher absorption and tremendously higher greenhouse effect, compared to water in vapor form that we cannot see. (Figure 3)

With intentional omission, many agencies do not like to mention water vapor because their aeroplanes release smoke filing the sky while flying and the nuclear centrals submerged the space exhaust fumes day and night.

There are many centrals that deflate the sky, turning the "greenhouse" to "coverhouse", impeaching the sun light to reach the earth. This cover house effect is dangerous because without sun no life on the earth.

Thus the nuclear centrals are big environmental polluters.

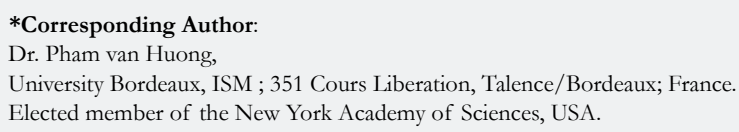

Copyright: Pham van Huong ${ }^{\circ}$ 2017. This is an open-access article distributed under the terms of the Creative Commons Attribution License, which permits unrestricted use, distribution and reproduction in any medium, provided the original author and source are credited. 
Figure 1. Mountain Everest, Himalaya.

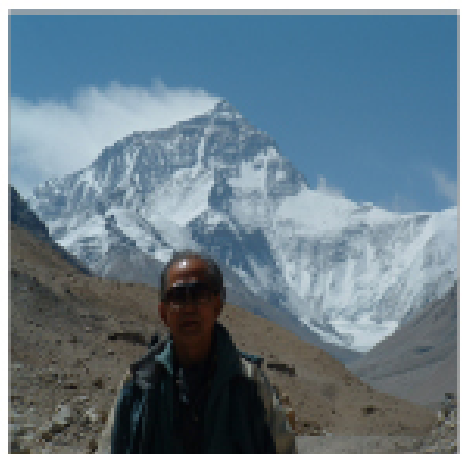

Figure 2. Light Absorption and Greenhouse Effect of $\mathrm{CO}_{2}, \mathrm{CH}_{4}$ and $\mathrm{H}_{2} \mathrm{O}$.

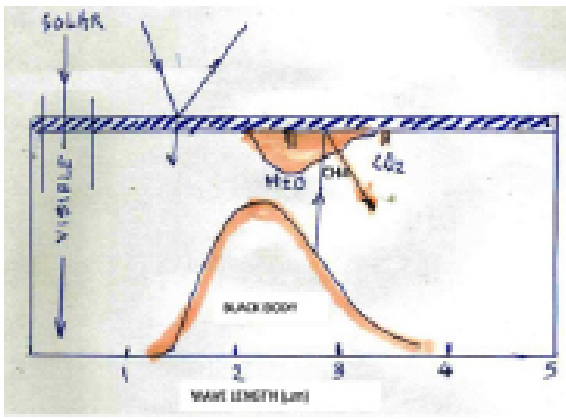

Figure 3. The Nuclear Plant Pollution.

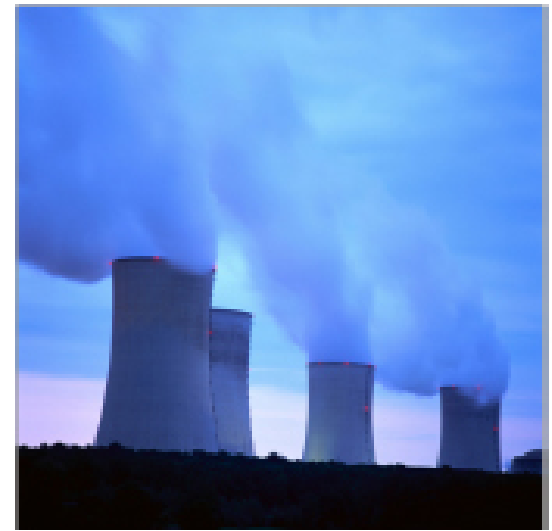

In an article about the natural disasters and human health security [1], published in the US a few weeks after President Barack Obama promised to announce the law on carbon tax. After this article so far we have not seen this act was born.

In the article, I have proposed to abandon the carbon tax and replace by what I called "Water Vapor tax", (wp tax )and force fuel companies and big fuel consumers to take responsibility and pay.

\section{Disasters}

Men-caused disasters: A central not only pollutes but also can cause great disasters for humanity.

Because technical loopholes, the Tchernobyl central in Russia explosed in 1986, killing 1,500 people and causing more than 600,000 people dead of cancer in thyroid, lung, blood, liver, etc
..., and more than 700,000 cancer people not yet dying. So far, Tchernobyl remains a radioactive area, land of death, desolation not know until never. I am also a thyroid victim though distant, but must take medication for life.

Conjugated men-made and natural disasters: The earth quake provokes a tsunami strucking the nuclear centrals in the area of Fukushima, northern Japan, causing explosion in 2011, killing 1,500 people and migration emergencies. Until last week, more than 230,000 families who have lost their homes are still uncomfortably lodged and not yet been settled.

Around the world, many nuclear centrals are located along the coast, to pump sea water for the cooling of their nuclear reactors like in Fukushima. In France, Pas de Calais region has four centers containing all 14 reactors on the coast. If there are high tides caused by the collision of the Eurasian and America continental floors, big disasters could happen. 


\section{Situation On Vietnam Territory}

Vietnam is a bit far from the meeting place of two continental floors, but the presence of hot springs at Binh Chau (Baria) and Thanh Thuy (Phu Tho) demonstrates that Vietnam Sea coast is also located on the furnace in the heart the earth. One other fact is new tectonic collisions often occur at new unpredictable places. The coast from Quang Nam to Ca Mau would be submerged by tsunamis. As predicted by many international organizations, these events could happen before 2050. (Figure 4, 5)

To get more information, I used the software of NASA, USA to calculate flood water level although rising for short time but with harmful consequences, for Mediterranean areas as well as for
Southeast Asia. For instance, Saigon and southern plains, with 4 meters waves, more than half of the land will be flooded. (Figure 6)

Other men-caused disasters: When I sell one nuclear central or important equipments such as aircrafts, warships, large digital machines, etc ... I can insert some cryptic components. Sometimes later, I can activate via satellite, the explosion of any above central or suspend the activities of any equipment as I like.

\section{Exposures to Dioxin and Paraquat Toxins}

After Seveso Italy, where the Dioxin incident has provoked deep emotion for millions people all over the world; the spraying of defoliants paraquat and orange agent Dioxin during the Vietnam

Figure 4. Water Levels Rising in Asia.

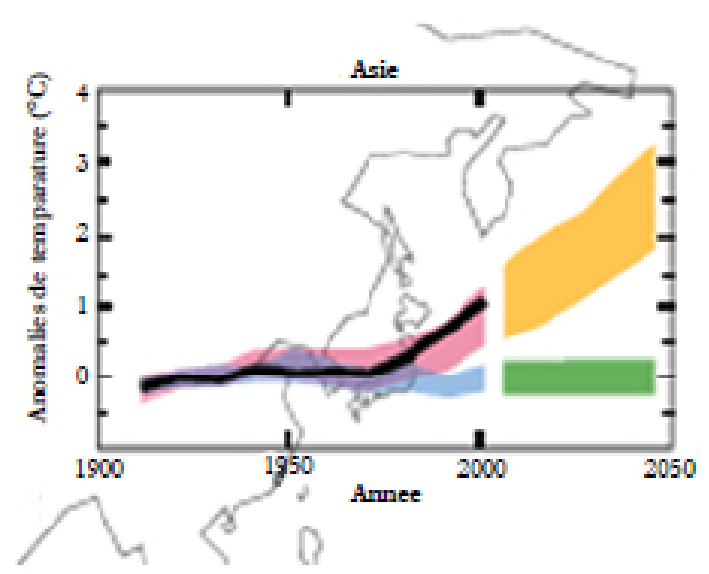

Figure 5. Four Meters Flood in the Southern France.

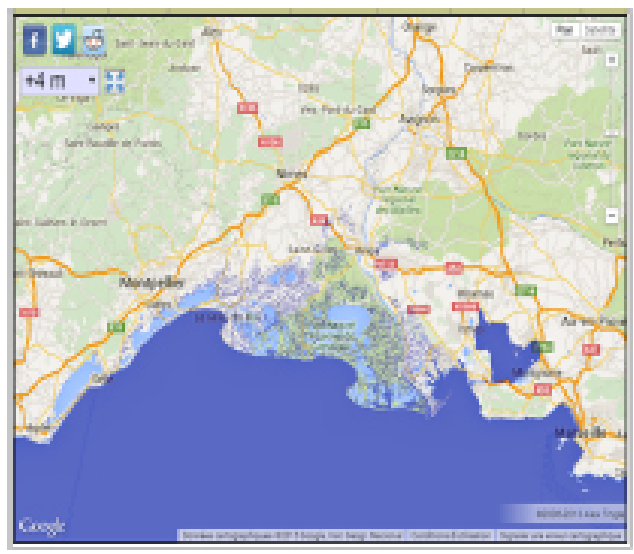

Figure 6. Water Level Teunami in South-East Asia.

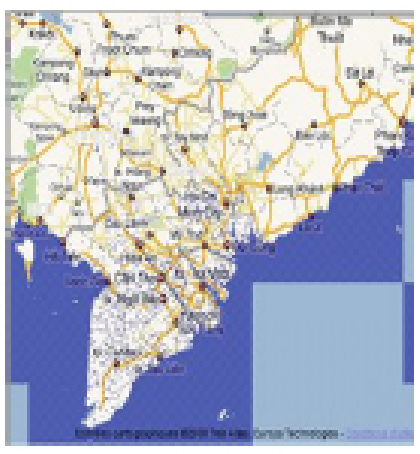

Saigon tody

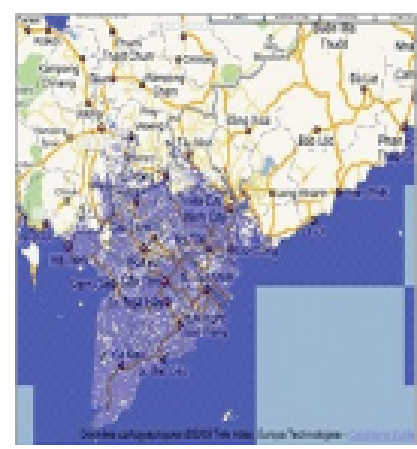

Srigon submerged 4 meters 
war, affected not only Vietnamese but also Americans who handed those dangerous chemical substances. Forty years have already gone but the remnants of the effects are still present, not only in the soil, in lakes, ponds, in abandoned rice fields and particularly in underground water pockets. The consumption of such water induced up to now, cancer and horrible baby malformations. (Figure 7)

One month ago one mediatic operation of Dioxin breaking of a contaminated soil clod is done at the Danang Airport. But the real solution in Vietnam needs hundreds more important operations.

The US military sprayed Agent Orange Dioxin and Paraquat toxins over $12 \%$ of the South and Middle Vietnam territory and directly kills a million people, indirectly hurting both Vietnamese people and US troops especially in Da Nang, Bien Hoa and Phu Cat airports. In Danang airport, 80 millions liters of Orange Agents were mixed, stored and loaded onto planes.

The concentration of sprayed Orange Agents was 400 times the globally accepted maximum standard:

The health effect of Dioxin exposures in Vietnam is the most awful disasters never seen on the world: Cancer, leukemia, birth defects in the children...[8-12].

Already more than forty years are going on, the defoliants are still present in soil, lakes, ponds and particularly in underground water pockets. Uninformed people continue to drink such water, to bath, to eat fishes, aquatic vegetables. Three millions of Vietnamese were exposed to Agents Orange, more than 150000 children were born with birth defects.

I have studied the destruction of rubber trees and pines cells because of toxins. With weak concentration, these trees do not lose their leaves. The later are even denser and the sap secretion is more abundant than usual. I also suggested sweep up toxins on big rubber trees, then after a few years, the trees will die soon and will be cut as wood. During the last four years, Ethephon which is known as grow regulator and maturing accelerator; has also been tested by brushing on trunk of rubber trees at Cat Lai, Dong Nai.
Although the defoliant mechanism is different than that of dioxin and paraquat but the effect is more or less the same.

In recent years, people began to use paraquat to sweep up the trunk surface of incense tree "gió bau" to increase the secretion of sap. However, when using this incense, paraquat residues can seriously harm the health of users. (Figure 8)

We must warn those who manipulate toxins and residential people of the sprayed areas to avoid them in future disasters such as cancer and birth defects.

Although the war has been over for 40 years, the victims and families have not received proper compensation.

\section{Rockets do not need a nuclear ogive}

In the old days many countries thought to use nuclear nose missile to devastate adversaries. Today, everyone knows that a simple rocket can usually be controlled by satellite to hit the target with an accuracy of a few square meters. Thus, if it shoots at the enemy's nuclear centrals, the centrals will explode like bombs.

\section{Drone}

Like the children's games without pilot, a drone carrying detonators can sabotage a nuclear central or an aircraft or warships. Done mission, Drone can receive order to return to the original base.

Nuclear centrals remain great dangers for humanity. (Figure 9)

\section{Conclusions}

The global warming continues to increase. The volcanic warming must be principally taken into account. In the greenhouse effect, it is a fault to only consider Carbon dioxide because the contribution of Water vapor is thousand times more important. Therefore Carbon tax must be substituted by Water-Vapor Tax WV Tax, due to its strong green house effect. All big polluters and combustible furnishers must pay. The plate tectonics can violently appear at

Figure 7. Vietnam Dioxin Victims.

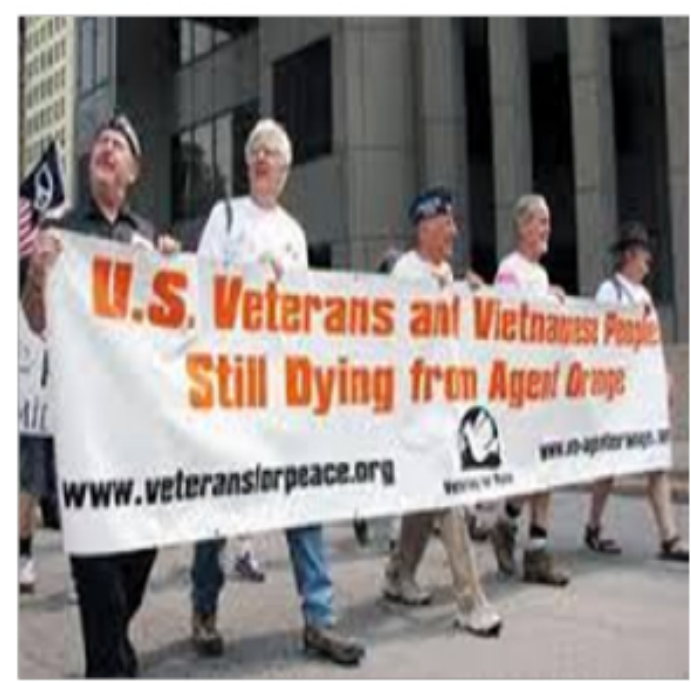


Figure 8. Big Rubber Trees Selected for Sweep up the Body with Low Concentration Toxins.

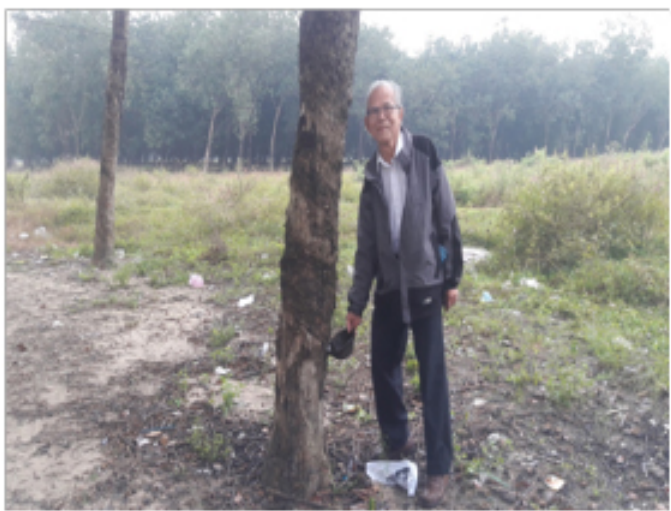

Figure 9. Drone without Pilot above a Rafale Aeroplane.

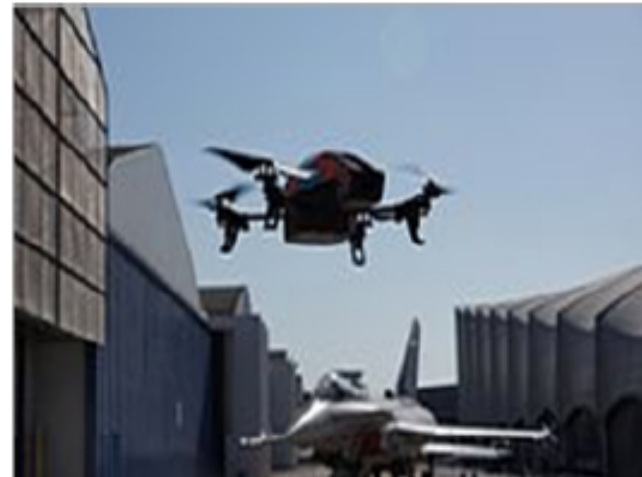

new sites and cause important tsunamis with damaging consequences. Finally the Dioxin and Paraquat exposures must be reduced to avoid harming cancer and birth malformation.

\section{Acknowledgments}

The authors express warm thanks to Dr C. Van Hai for helpful discussions.

\section{References}

[1]. Pham van Huong (2015) Climate Change through the studies of Volcano Rocks and Blue Icebergs. Int J Natural Disaster Health Secur. 2(1): 1-5.

[2]. Huong PV, Verma AL (1993) Presence of tri-iodide ions in iodine-intercalated IBi2Sr2CaCu2O8 superconductors. Phys Rev B Condens Matter. 48(13): 9869-9872.

[3]. Huong PV, Ajayan PM, Cavagnat R, Stephan O (1995) Temperature-dependent vibrational spectra of carbon nanotubes. Phys Rev B Condens Matter. 51(15): 10048-10051.

[4]. Choy JH, Kim YI, Hwang SJ, Huong PV (2000) Trigonal planar (D-3h)
AuI3 complex stabilized in a solid lattice. J Phys Chem B. 104(31): 7273 7277.

[5]. Choy JH, Kim YI, Hwang SJ, Muraoka Y, Ohnishi N, et al., (2000) HRTEM and micro-Raman studies on superconducting-superionic conductingnanohybrid, Ag1.17I1.54Bi2Sr2CaCu2Oy. J Phys Chem B. 104(39): 9086-9090.

[6]. Kwon SJ, Choy JH, Jung DW, Huong PV (2002) Heterostructured high-Tc superconducting nanohybrid: (Me3S)2 HgI 4- $\mathrm{Bi} 2 \mathrm{Sr} 2 \mathrm{CaCu} 2 \mathrm{Oy}$. Phys Rev B. 66(22): 224510-224522.

[7]. Hwang J, Kwon CW, Portier J, Campet G, Park HS, et al., (2002) Local crystal structure around manganese in new potassium-based nanocrystalline manganese oxyiodide. J Phys Chem B. 106(16): 4053-4060.

[8]. Huong PV (1989) Metallo-organic complexes and Carcinogenesis . Molecules in Physics, Chemistry and Biology. Springer, Nederlands. 87-109.

[9]. Huong PV (1986) Organometallic Interactions in Biological Systems. J Mol Struct. 141: 203-209.

10]. Plouvier SR, Lambert P (1988) Organometallic complexes of Microbial origin, identified in malignant tumors and leukemia by Raman and X-Ray microspectroscopy. XVII International Congress of Pathology, Dublin.

[11]. Huong PV (1989) Raman Spectroscopy for Biological Applications in Analytical Raman Spectroscopy. Wiley, New York. 114: 397-423.

[12]. Pham v Huong, VT Kim Ngoc, Vu Hung Thai, Thanh le T, Phan Th (2015) Study of Colorectal Cancer by Nuclear Magnetic Resonance . Int J Magn Nucl Sci. 1(1): 1-5. 